\title{
JUVENTUDE E PROJETO DE VIDA: TRAJETÓRIAS NA PESQUISA ACADÊMICA BRASILEIRA
}

\author{
YOUTH AND LIFE PLANNNING: TRAILS IN THE BRAZILIAN ACADEMIC RESEARCH \\ JUVENTUD Y PROYECTO DE VIDA: TRAYECTORIAS EN LA INVESTIGACIÓN ACADÉMICA \\ BRASILEÑA
}

\author{
Érika de Sousa Mendonça* \\ Renata Paula dos Santos Moura** \\ Stellamary Brandão Rodrigues Gaia*** \\ Jaileila de Araújo Menezes ${ }^{* * * *}$
}

\begin{abstract}
RESUMO
Objetiva-se refletir o campo-tema juventude e projeto de vida, com base em publicaçōes científicas brasileiras da última década, localizadas na Biblioteca Digital Brasileira de Teses e Dissertaçôes e em revistas de referência nas áreas de Psicologia, Educação e Ciências Sociais. Identificaram-se objetivos, referenciais teóricos, metodologia e prevalências de instituições, áreas de conhecimento e período de publicação. Em sintonia com as pesquisas de estado da arte, construiu-se um quadro panorâmico que destaca temas como educação, políticas públicas, violência, pobreza e participação em projetos sociais, em estudos e pesquisas que utilizaram multimétodos com enfoques qualitativos e realizados com maior ênfase a partir de 2006. Uma interlocução com conjunturas político-econômicas e sociais do período de 2002 a 2012 indicam maior problematização da juventude a partir de 2005, embora, nos estudos acadêmicos, a referência preponderante seja ao jovem como objeto de estudo, isentando-se da reflexão política sobre a juventude.
\end{abstract}

Palavras-chave: Juventude. Projeto de vida. Estado da arte.

\section{ABSTRACT}

This study aims at raising reflections on the theme youth and life planning, based on Brazilian scientific publications made public in the last decade,

\footnotetext{
Texto recebido em 13 de dezembro de 2014 e aprovado para publicação em 20 de junho de 2016.

"Doutora em Psicologia pela Universidade Federal de Pernambuco (UFPE), professora adjunta do Curso de Psicologia da UFPE. E-mail: erika.mendonca@hotmail.com.

**Doutoranda em Educação no Programa de Pós-Graduação em Educação da UFPE, atuou como professora substituta no Departamento de Administração Escolar e Planejamento Educacional do Centro de Educação da UFPE. E-mail: repaulasmoura@ hotmail.com.

***Graduada em Pedagogia pela UFPE, atuou como apoio pedagógico no Centro de Estudos em Educação e Linguagem (CEELUFPE).E-mail: stellamarybrandao@hotmail.com.

**** Doutora em Psicologia pela Universidade Federal do Rio de Janeiro (UFRJ), professora associada da UFPE, vinculada ao Departamento de Psicologia e Orientações Educacionais do Centro de Educação e ao Programa de Pós-graduação em Psicologia do Centro de Filosofia e Ciências Humanas. E-mail: jaileila.araujo@gmail.com.
} 
available from the Brazilian Digital Library of Theses and Dissertations and reference journals about Psychology, Education and Social Sciences. Objectives, theoretical references, methodology and prevailing institutions, fields of knowledge and publication dates have been highlighted. Complying with the state-of-the-art research, a panoramic framework was established highlighting topics such as education, public policies, violence, poverty and participation in social projects, in studies and research that used multimethods with qualitative approaches which were carried out with greater emphasis from 2006 on. Intercommunication involving political-economic and social contexts in the period from 2002 to 2012 outstands a greater level of problematization of the youth from 2005 on, although, in academic studies the youth is the leading reference as an object of study, keeping under exemption the political reflection on youth.

Keywords: Youth. Life project. State of the art.

\section{RESUMEN}

Se pretende reflexionar sobre el campo-tema juventud y proyecto de vida, desde las publicaciones científicas brasileñas de la última década, ubicadas en la Biblioteca Digital de Tesis y Disertaciones y en publicaciones de referencia en los campos de la Psicología, Educación y Ciencias Sociales. Fueron identificados objetivos, referenciales teóricos, metodología y prevalencias de instituciones, áreas de conocimiento y período de publicación. En consonancia con las investigaciones de estado del arte, se construyó un marco panorámico que destaca temas como educación, políticas públicas, violencia, pobreza y participación en proyectos sociales, en estudios e investigaciones que utilizaron multimétodos con enfoques cualitativos y realizados con mayor énfasis a partir de 2006. Una interlocución con coyunturas político-económicas y sociales del periodo 2002-2012 indican mayor cuestionamiento y problematización de la juventud, a partir de 2005, aunque en los estudios académicos la referencia predominante es al joven como un objeto de estudio, exentándose de la reflexión política sobre la juventud.

Palabras clave: Juventud. Proyecto de vida. Estado del arte.

\section{UMA INTRODUÇÃO AO ESTUDO E SUAS FONTES DE PESQUISA}

interesse em desenvolver um estudo relacionado à temática juventude
e projeto de vida surgiu a partir de discussões realizadas no Grupo de
Estudos e Pesquisas sobre Poder, Cultura e Práticas Coletivas (Gepcol). Esse grupo de pesquisa (composto por docentes e discentes pesquisadores da 
Universidade Federal de Pernambuco) tem como objetivo investigar, em meios urbanos e rurais, as configuraçōes do poder em diferentes dimensōes das relações sociais e práticas coletivas, culturais e políticas. No ano de 2007, parte das pesquisas do grupo passou a focar questões de juventude e projeto de vida no contexto do movimento hip-hop. A pesquisa versava sobre $A$ arte na politica: um estudo do movimento hip-hop na cidade do Recife e estava estruturada em torno de três eixos:

a) o subjetivo: interessado nas conexões operadas pelos jovens a fim de modificar suas formas de vida, a partir da elaboração de projetos de vida inspirados em modos de existência criativos;

b) o político: reflete sobre a arte como forma de mobilização da comunidade, expondo as problemáticas locais;

c) o cultural: problematiza os elementos da cultura hip-hop (rap, break, grafite, $D J$ ) como provocadores do senso e posicionamentos críticos assumidos e disseminados pelos jovens em suas produçôes.

Pelo eixo subjetivo, foi possível explorar as contribuições do movimento hiphop para a vida dos jovens, seja pela ampliação de suas redes de sociabilidade como também pela construção de percepções críticas sobre o contexto de suas vidas e de suas comunidades. Nesse sentido, o projeto de vida foi entendido de modo ampliado e transversalizado por acontecimentos sociais, econômicos, históricos, culturais e políticos (Velho, 1997). Portanto assumimos como ponto de partida que o projeto de vida é subjetivo, mas não individual, pois ele se constrói nas conexões que o sujeito estabelece por um campo de relações macrossociais e interrelacionais (família, escola, igreja, amigos, relações afetivo-sexuais, movimentos sociais, entre outros). Partindo-se dessa perspectiva, buscamos identificar que outras noções ou relações entre projeto de vida e juventude vêm sendo construídas em pesquisas acadêmicas nacionais.

Apesar de termos realizado pesquisas empíricas, investigando projetos de vida em construção por jovens, interessava-nos também conhecer outras pesquisas sobre o tema: o que vem sendo estudado? Como vem sendo pesquisado? Onde e em torno de que essas discussões têm circulado? Eis que optamos pela realização de uma pesquisa de estado da arte.

Estudos sobre o estado da arte têm se destacado no meio acadêmico, nos últimos anos, por proporcionar uma visão abrangente da produção científica a respeito de um determinado tema. Ferreira (2002) tece as seguintes consideraçôes sobre esse tipo de estudo: 
Definidas como de caráter bibliográfico, elas parecem trazer em comum o desafio de mapear e de discutir uma certa produção acadêmica em diferentes campos do conhecimento, tentando responder que aspectos e dimensões vêm sendo destacados e privilegiados em diferentes épocas e lugares, de que formas e em que condições têm sido produzidas certas dissertações de mestrado, teses de doutorado, publicações em periódicos e comunicaçôes em anais de congressos e de seminários. Também são reconhecidas por realizarem uma metodologia de caráter inventariante e descritivo da produção acadêmica e científica sobre o tema que busca investigar, à luz de categorias e facetas que se caracterizam enquanto tais em cada trabalho e no conjunto deles, sob os quais o fenômeno passa a ser analisado (p. 258).

Assim, o emprego dessa modalidade de pesquisa foi motivado sobretudo pelo desafio de conhecer "o já construído e produzido para depois buscar o que ainda não foi feito" (Ferreira, 2002, p. 259), permitindo-nos realizar um levantamento metodológico minucioso e uma problematização das produções acadêmicas em determinados temas.

As bases de dados consultadas neste estudo foram a Biblioteca Digital Brasileira de Teses e Dissertações (BDTD) e as revistas científicas: Psicologia e Sociedade, Revista Brasileira de Educação e Sociologia e Politica. A escolha da BDTD como fonte de pesquisa se deu por esta ser identificada como o maior acervo virtual de dissertações e teses brasileiras. A escolha das revistas esteve em consonância com a reverberação da temática juventude na área da Psicologia (nesse campo discursivo, as questôes de juventude são predominantemente tratadas em relação com as problemáticas da adolescência, o que, por vezes, representa a aplicação de uma lógica desenvolvimentista que oblitera a agentividade juvenil); na área da Educação, em que as questôes de juventude comumente ganham feição junto aos aspectos formativos de escolarização e ensino técnico-profissional com vistas ao mundo do trabalho. Aqui as articulações entre juventude e projeto de vida ganham contornos clássicos na discussão da escola como instância de socialização fundamental nas sociedades ocidentais modernas; por fim, nas áreas da Sociologia e Política, temos a chance de acessar o debate geracional, em que juventude se coloca como uma condição que ganha contornos históricos e de vivências socialmente projetadas como típicas para um determinado grupo. Os aspectos políticos são abordados em diversas frentes, desde a participação sociopolítica que compreende as reflexões sobre a agentividade juvenil em suas possibilidades e desafios até a elaboração de políticas públicas que têm os jovens como alvo de ações governamentais. Entendemos que abordar a temática juventude e projeto de vida a partir do circuito discursivo presente nas áreas da Psicologia, Educação, Sociologia e Política permite acessar dimensões macro e micropolíticas, simbólicas e objetivas que participam da elaboração de projetos de vida nesse momento biográfico que é a juventude. 
Estabelecemos um recorte temporal da pesquisa em dez anos (2002-2012), incluindo, nesse sentido, materiais apresentados ao portal BDTD desde sua existência (2002). Propomo-nos a realizar uma reflexão crítica dos dados obtidos, lendo-os à luz de realidades sociais e políticas do nosso país, ao longo desta década, que foi nosso recorte temporal. Buscamos também um olhar ampliado à juventude como condição juvenil - expectativas socialmente produzidas para um determinado segmento etário (os jovens) - e situação juvenil - trajetórias efetivas de jovens que são cumpridas a partir de seus recursos cotidianos em atenção às vivências de diferença e desigualdades sociais que experienciam (Abramo \& Branco, 2005).

Utilizamos uma abordagem com enfoque numérico e analítico, de modo que a organização do material favorecesse leituras que se complementavam: foram usados dados estatísticos para indicar o quantitativo de trabalhos produzidos ou o período de publicação, ao mesmo tempo em que a esses dados articulavam-se aspectos históricos da política nacional de juventude e construíam-se reflexões que se articulavam teoricamente a estudos acadêmicos de referência no trato da juventude. Assim é que a dimensão quantitativa constituiu questôes a serem aprofundadas qualitativamente e vice-versa, conforme orientam Minayo e Sanches (1993).

\section{DOS ESTUDOS IDENTIFICADOS: ENTRE O OLHAR SOBRE OS JOVENS E A ANÁLISE SOBRE A JUVENTUDE}

Definidas nossas bases de investigação, realizamos o levantamento de dissertaçôes e teses entre os meses de maio e junho de 2012. Iniciamos nossa pesquisa a partir de dois descritores, o primeiro composto dos termos "juventude e projeto de vida" e, em seguida, com os termos "jovens, e projeto de vida". $\mathrm{Na}$ primeira pesquisa, foram identificadas 14 teses e 45 dissertações; na segunda, foram encontradas 48 teses (entre as quais se encontram as teses identificadas inicialmente, na primeira pesquisa) e 155 dissertações. ${ }^{1}$ Realizamos a leitura dos resumos dos trabalhos mapeados na pesquisa estado da arte. É certo que alguns achados levaram a um maior aprofundamento, visto que, por vezes, os resumos não contemplavam as questões que problematizávamos ou não deixavam claro o objeto de estudo, então adentrávamos o texto. Nesse sentido, a filtragem dos resumos se deu a partir da leitura minuciosa destes e a identificação do objeto de pesquisa nas produçôes, já que, por vezes, os temas (“juventude e projeto de vida" e "jovens e projeto de vida") distanciavam-se da problematização desses textos.

1 Cabe aqui informar que foram lidos os resumos das 155 dissertaçōes encontradas e sobre elas realizou-se uma filtragem, de modo a identificar aquelas que mais se aproximavam do interesse desta pesquisa (no caso, juventude e projetos de vida). Após essa filtragem, centramos nossos estudos em 49 dissertaçōes. 
A pesquisa dos artigos científicos foi realizada nas revistas científicas Psicologia e Sociedade, Revista Brasileira de Educação e Sociologia e Politica. Também nesses ambientes, a pesquisa se realizou com base nos descritores "juventude e projeto de vida", tendo sido localizados 24 trabalhos; na segunda pesquisa, baseada nos termos "jovens e projeto de vida", foram encontrados 67 artigos, distribuídos entre as três revistas, havendo uma maior concentração na área de Psicologia social, com 45 estudos identificados.

Nesse contexto, pela análise do material encontrado, o primeiro dado que nos chamou a atenção foi o elevado número de pesquisas que tratam do jovem, mas não da categoria juventude, ou seja, o público jovem tem sido alvo de pesquisas nas Ciências Humanas, Sociais e Educação, contudo a categoria psicossociológica juventude não tem sido amplamente problematizada. Compreendemos a juventude como um momento biográfico que não se reduz a uma passagem; ela assume uma importância em si mesma. Como momento biográfico, as vivências de juventude compreendem as tensões entre as expectativas sociais (condição juvenil) e as formas singulares da vivência da juventude influenciada pelo meio social concreto e pela qualidade das trocas que este proporciona (situação juvenil) (Dayrell, 2002; Peralva, 2007).

O termo juventude começou a ser categorizado no início do século XX. Por se tratar de uma categoria social, ela se manifesta de modos diferentes de acordo com o momento vivido pela sociedade. Não se pode dizer que existe uma juventude, mas várias juventudes:

A juventude é uma categoria socialmente construída. Ganha contornos próprios em contextos histórico-sociais distintos, e é marcada pela diversidade nas condições sociais [...], culturais [...], de gênero e até mesmo geográficas, dentre outros aspectos. Além de ser marcada pela diversidade, a juventude é uma categoria dinâmica, transformando-se de acordo com as mutações sociais que vem ocorrendo ao longo da história (Dayrell, 2007, p. 4).

A noção de juventude e as formas como ela será tratada dependerão, portanto, da organização da sociedade num determinado momento histórico e da dinâmica de suas relaçôes de poder. Diante das variadas imagens que se fazem do "ser ou do vir a ser jovem”, está uma com forte adesão social que percebe a juventude como um momento de crise, uma fase difícil, dominada por conflitos com a autoestima e com a personalidade. Por essa perspectiva, a juventude tende a ser considerada como um momento de distanciamento da família (Dayrell, 2007). Para esse autor, contudo, essas imagens devem ser postas em questionamento, uma vez que os modelos socialmente construídos trazem o risco de analisar os 
jovens de maneira negativa, buscando neles características universais para atingir um determinado modelo de "ser jovem".

A juventude, pois, é mais do que puramente uma condição biológica, ela está referenciada nas práticas discursivas que sustentam modelos de ser e existir, mas também (e por ser o discurso um campo de conflitualidade social) abre a possibilidade de modos alternativos para sua definição. Peralva (2007) e Dayrell (2007) entendem ainda que a juventude é, ao mesmo tempo, uma condição social e um tipo de representação, em que o dito caráter universal dado pelas transformações do indivíduo numa determinada faixa etária, nas quais completa o seu desenvolvimento físico e enfrenta mudanças psicológicas, difere em cada sociedade, em um tempo histórico determinado.

Tendo como ponto de partida tais discussões em que a juventude deve ser vista sempre de modo contextualizado, com base em vivências e situações socialmente circunscritas, chama-nos a atenção que poucos são os estudos em teses, dissertações e artigos da última década, no Brasil, que problematizam a juventude. As pesquisas destacam "o jovem” e com base em um padrão etário, deixando de abordar o campo-tema juventude aqui entendido como arena éticopolítica de debates e práticas sociais em torno da condição (aspectos gerais da juventude) e situação juvenil (aspectos específicos das condições de existência dos jovens).

Tomar a juventude como campo-tema consiste em problematizar o processo mesmo de construção de conhecimento sobre a juventude como perpassado por relações de saber-poder (Spink, 2003). Mais que a produção de conhecimento em si, importa considerar o grau de compromisso que esta tem com a justiça social, entendendo que o saber acadêmico está perpassado por práticas sociais e políticas, sofre regulações discursivas de vários setores e pode responder a eles de diferentes formas. Assim, quando as pesquisas acessam os jovens sem problematizar o campo-tema juventude, elas se reduzem a tratá-los como objetos empíricos e, nesse caso, a referência a eles é feita na parte da metodologia como "sujeitos da pesquisa" e não se produz uma reflexão sobre as condições sociopolíticas e seus efeitos sobre a vida dos jovens.

O lastro histórico-político está ausente em um número significativo de produções acadêmicas acessadas, o que nos leva a refletir sobre o processo de produção de conhecimento referenciado na busca de verdades absolutas e universais. Advogamos que a pluralidade de vozes que constituíram e que mantêm 
a categoria juventude e a pergunta sobre os desdobramentos das pesquisas e mesmo as tensões entre pesquisadores e jovens ficam invisíveis quando se considera o objeto jovem apartado do campo-tema juventude (Mayorga, 2013).

\section{DO QUE TRATAM OS ESTUDOS QUE ENVOLVEM REFLEXÕES SOBRE JOVENS E PROJETOS DEVIDA: INTERLOCUÇÕES COM A LITERATURA ESPECIALIZADA}

As bases de dados virtuais que serviram de suporte a este estudo permitem que o pesquisador insira algumas informaçôes ou "filtros" daquilo que pretende pesquisar. Essas informações podem ser: termos (ou assuntos), tipo de estudo (dissertação ou tese), universidade, data (ou período de tempo determinado), autor. Para o estudo, nosso foco principal esteve nos termos "jovens e projetos de vida", ${ }^{2}$ considerando o período entre 2002 e 2012.

No portal da BDTD, ainda há um recurso que nos permite selecionar em que ordem desejamos que os estudos pesquisados apareçam: se por data, em ordem crescente ou decrescente, por exemplo, ou se por ordem de relevância. Este último foi o critério por nós adotado. O site da BDTD ainda apresenta um instrumento chamado "percentual de relevância", baseado num cruzamento de informações (feito virtualmente pelo sistema) entre a tese ou dissertação cadastrada e o termo indicado por nós. Assim, percebemos que muitos trabalhos identificados pela BDTD como de alta relevância (80\% de relevância com o assunto pesquisado, por exemplo) não tinham como tema principal “jovens e projetos de vida”, o que, inclusive, levou-nos à inquietação: como o sistema classifica esses índices de relevância?

Em alguns casos, esse era o tema principal; noutros, era um tema secundário. Havia, ainda, dissertaçôes e teses cujos resumos sequer ofereciam pistas sobre projeto de vida de jovens. Os temas e subtemas mais frequentes abordados nesses tipos de estudos e também nos artigos científicos foram identificados pela leitura dos títulos e resumos, como informamos anteriormente. A partir dessa leitura, construiu-se uma tabela de dados com as seguintes localizações: temas principais e secundários da pesquisa; instituição de ensino onde o estudo se desenvolveu; área de conhecimento; data de publicação e, ou, defesa; objetivos e metodologia de trabalho; e referencial teórico adotado. Durante esse processo, procuramos dar atenção para termos que se repetiam com mais frequência nos resumos.

\footnotetext{
2 Inicialmente, colocamos os termos "juventude e projeto de vida", mas como foram encontrados poucos trabalhos, optamos por pesquisar "jovens e projeto de vida", pois assim os estudos se ampliaram e, principalmente, englobaram os primeiros, como dito anteriormente.
} 
Foram identificados cinco temas principais, todos inter-relacionados, conforme indica a figura 1 :

Figura 1. Temas e subtemas mais frequentes nos estudos identificados

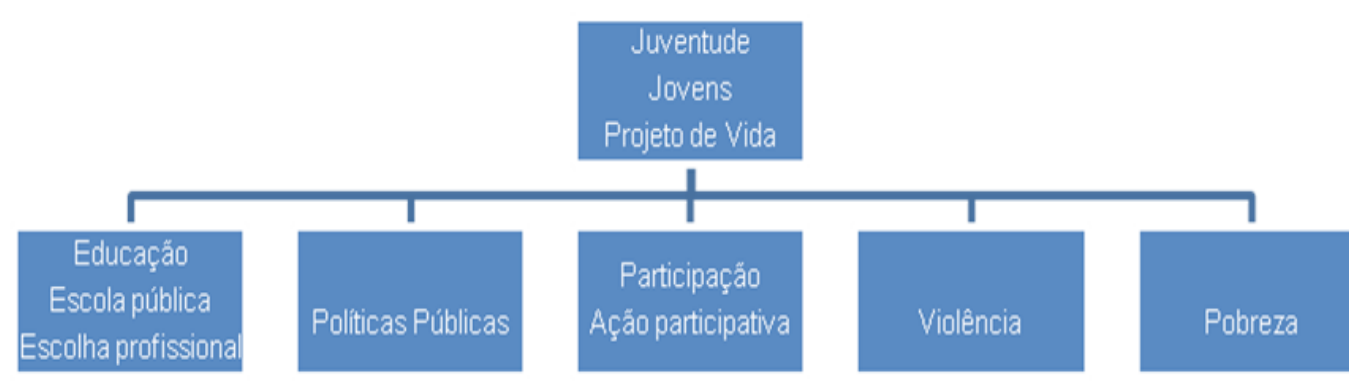

Fonte: elaborado pelas autoras.

Os temas e subtemas mais recorrentes nas produções acadêmicas analisadas estão relacionados à educação, tratando, na maioria das vezes, do contexto de escolas públicas, de estudo formal (com grande destaque à alfabetização de jovens e adultos) e também informal, a partir de projetos sociais ou medidas socioeducativas em casos de jovens em conflito com a lei. Outro tema bastante tratado nesses estudos se refere à escolha profissional. Percebe-se, desse modo, que a escola acaba sendo a instituição identificada como responsável pelo projeto de vida dos jovens, levando em conta, possivelmente, a preparação para o mundo do trabalho e a lógica do mercado.

As instituições de ensino e os projetos sociais também aparecem relacionados às políticas públicas que ajudam na inserção social de jovens e como alternativas no enfrentamento à violência. Notamos, ainda, uma concentração de produções no campo educacional que apresenta a escola como uma instituição que deveria dialogar mais com os jovens. Como dito acima, os estudos e temas destacados nas produções acadêmicas analisadas intercruzam discussões de educação, políticas públicas e violência.

Dayrell (2005) ressalta que a escola pouco conhece o jovem que a frequenta, a sua visão de mundo, os seus desejos, o que faz fora da instituição. Ao mesmo tempo, predomina uma representação negativa e preconceituosa nessas instituições em relação à juventude e, especialmente, em relação ao jovem pobre, que é visto sob a perspectiva da falta, da incompletude, da desconfiança, o que torna ainda mais difícil para a escola posicioná-lo como sujeito e trabalhar com ele. Encontramos, aqui, articulações que sinalizam outro tema bastante enfatizado nos artigos, dissertaçôes e teses: o jovem pobre.

No olhar sobre o jovem pobre, mostra-se evidente, também, a associação que se faz entre a pobreza e contextos de violência, assim como a necessidade de 
intervenções estatais, de políticas públicas, de assistência, de educação, seja ela pela escola pública ou projetos sociais, o que nos leva a indagar: por que pesquisas científicas privilegiam o estudo de jovens pobres? Enquanto se privilegiam os estudos sobre jovens pobres, não se reafirma o jovem pobre como um problema social?

A esse respeito, Telles (2007) alerta que a versão brasileira das metamorfoses da questão social se configura como programas sociais que se multiplicam pelas periferias afora e em seu entorno, para intervir sobre a vida de crianças e jovens pobres. Por todos os Estados e Municípios, há associações ditas comunitárias que tratam de se converter à lógica gestionária do chamado empreendedorismo social, credenciando-se como "parceiras" dos poderes públicos locais e disputando recursos junto a fundações privadas (e à chamada filantropia empresarial) e agências multilaterais. Tudo isso em interação com miríades de práticas associativas e suas articulações políticas, partidos e seus agenciamentos locais e, claro, a quase onipresença de organizaçôes não governamentais vinculadas a circuitos e redes de natureza diversa e extensão variada.

Boghossian e Minayo (2009) destacam que:

A participação dos jovens na elaboração e implementação de projetos, programas e políticas que os afetam tem figurado cada vez mais no discurso dos diversos setores sociais que estabelecem como foco de atenção a juventude, como as organizações internacionais, os governos, as universidades e as entidades da sociedade civil. Percebe-se, nesse contexto, a grande diversidade de propostas direcionadas a estimular a participação juvenil e a abertura de espaços para essa participação, desenhando-se o desafio de problematizar seus objetivos e estratégias, seus avanços e principais entraves (Boghossian \& Minayo, 2009, p. 412, grifo nosso).

É assim que apresentamos a última temática destacada nos estudos realizados: a participação juvenil em projetos sociais. Essa participação ora é vista numa perspectiva a que chamaremos negativa, pois ela mostra essa participação como saída possível aos jovens para que não se envolvam em problemas sociais, como a marginalidade e a violência (responde-se, assim, ao jovem pobre em sua lógica de fracasso anunciado). Mas por outro lado, essa participação é também apresentada de maneira positivada, quando o jovem é destacado em suas potencialidades de provocador de mudanças sociais.

Essa ambígua abordagem ao jovem (a saber: problema e potência) circunda as pesquisas sobre essa parcela da população. $\mathrm{O}$ jovem brasileiro representa a camada do estrato societário que está inserida nas transformaçôes sociais, culturais e econômicas que trazem novos aspectos para o viver em sociedade (Castro \& Correa, 2005). A sociedade contemporânea promove, em relação à sua juventude, um paradoxo. De um lado, tem-se uma cultura marcada por uma 
supervalorização do jovem e do "ser jovem" que se expande como valor canônico para todos os grupos de idade e se manifesta em múltiplas representaçôes socioculturais, da publicidade à moda, da música às produções televisivas. Essas dimensóes, às quais se relacionam valores de vitalidade, dinamismo e criatividade, articulam-se a outras características dos tempos atuais: a valorização social do tempo livre, do lazer e do ócio. A juventude seria, pois, o grupo social emblemático, com legitimidade para assumir todas essas dimensões.

Esse protagonismo da condição juvenil não coincide, entretanto, com sua inserção socioeconômica real, em que a falta de horizontes profissionais, as altas taxas de desemprego juvenil, a falta de equipamentos socioculturais, a extensão da vacuidade têm alimentado os fantasmas da marginalidade, da delinquência e da possibilidade de rupturas da ordem social (Fausto Neto \& Quiroga, 1998).

Essas diferentes ênfases no olhar sobre a juventude revelam a complexidade do tema e a variedade de focos nos estudos acadêmicos brasileiros.

\section{A JUVENTUDE NA LITERATURA E EM CONTEXTOS SÓCIO- HISTÓRICO-POLÍTICOS BRASILEIROS}

Como nosso objetivo é ir além de um levantamento puramente quantitativo ou descritivo dos dados encontrados, buscamos construir, no decorrer deste artigo, algumas reflexôes sobre os principais temas de pesquisas; sobre um olhar que predomina em relação aos jovens pobres; sobre as inter-relações entre estudos de projeto de vida e educação ou escolha profissional; sobre uma maior concentração desses estudos nos últimos cinco anos. Propomo-nos, agora, a buscar problematizar a produção acadêmica localizada em articulação a contextos sócio-histórico-políticos no Brasil.

A juventude, como tema de relevância social, emerge como efeito do processo de redemocratização da sociedade brasileira, após os debates mais intensos sobre a consolidação dos direitos de cidadania, que se materializaram na Constituição Federal, no fim da década de 1980. Vale ressaltar que os movimentos sociais foram os sujeitos desses processos, e se articularam, sobretudo, pela retomada da democracia e pela constituição de políticas setoriais como educação, saúde, trabalho, entre outras. Nesse sentido, nas décadas de 1970 e 1980, os setores organizados reconhecidos como de forte participação juvenil estavam articulados, principalmente, em torno dos movimentos estudantis e dos partidos políticos. Assim, apesar de serem jovens os sujeitos presentes nesses movimentos, ainda não apresentavam reivindicações direcionadas para a juventude. 
Em relação ao cenário mundial, foi a partir de 1965 que a Organização das Nações Unidas (ONU) iniciou articulações e compromissos voltados para a juventude. Isso ocorreu quando seus Estados-membros assinaram uma declaração, considerando a necessidade de priorizar as articulaçôes entre a juventude e os ideais de paz, respeito mútuo e compreensão entre os povos. Entretanto, somente em 1985, com a instituição pela ONU do Ano Internacional da Juventude, é que o tema conseguiu alcançar visibilidade. Em seguida, foram desencadeados outros mecanismos e acordos internacionais que promoveram o reconhecimento dos direitos humanos em relação com a temática das juventudes, o que impactou em ações de países da América Latina. Em particular, no Brasil, tanto a infância como a juventude somente passaram a ser reconhecidas como referenciando sujeitos de direitos a partir da Constituição Federal de 1988 e do Estatuto da Criança e do Adolescente, que data de 1990.

Em nossa história recente e considerando o período que utilizamos para a busca das produçóes acadêmicas (2002 a 2012), cujo tema principal ou secundário se centra em jovens e projetos de vida, mapeamos um quadro sociopolítico que indica conquistas da juventude no Brasil e colabora para o entendimento do crescimento das pesquisas sobre o tema a partir de 2006.

No ano de 2005, o lançamento do Programa Nacional de Inclusão de Jovens (Projovem); a criação da Secretaria Nacional de Juventude e a criação do Conselho Nacional da Juventude (Conjuve). Em 2007, o lançamento do Projovem Integrado, e o Brasil sediando a 1a Reunião Especializada da Juventude do Mercado Comum do Sul (Mercosul). No ano seguinte, a realização da $1^{\text {a }}$ Conferência Nacional de Juventude, do $1^{\text {a }}$ Pacto pela Juventude, e o Brasil sediando a 4a Sessão da Reunião Especializada da Juventude no Mercosul.

Em 2009, o Brasil sediou o 2a Encontro de Parlamentares Ibero-Americanos de Juventude e, em 2010, assumiu a presidência da Reunião Especializada de Juventude do Mercosul (REJ); realizou o $2^{\circ}$ Pacto pela juventude; aprovou a Proposta de Emenda à Constituição (PEC) da juventude; foi o ano Internacional da juventude; o País também sediou a Pré-Conferência da Juventude das Américas e Caribe; a $1^{\text {a }}$ Mostra do Projovem Urbano; passou a integrar a Organização Ibero-Americana de Juventude (OIJ) e assumiu vice-presidência da OIJ na 15a Conferência Ibero-Americana de Ministros e Responsáveis de Juventude. E em 2011, ocorreu a aprovação do Estatuto da Juventude pela Câmara Federal e a 2a Conferência Nacional de Juventude, entre outras conquistas que resultaram de lutas de diferentes grupos organizados da sociedade brasileira. 
Percebemos que, apesar de esses marcos demostrarem avanços em relação ao campo da juventude, ainda é incipiente a participação dos jovens em alguns espaços de luta por direitos. Existem grupos organizados (coletivos, organizações não governamentais, etc.) que participam ativamente desses espaços, e isso é um indicador de que a juventude vem ganhando força nas discussões políticas, construindo espaços de mobilização e participação social, garantindo, por vezes, as tão almejadas possibilidades de exercer vez e voz em espaços públicos, provocando "tensionamentos" (sobretudo de níveis de poder diferenciados) e demarcando "territórios" e ações que passam a visibilizar essa categoria social. Entretanto a participação ainda precisa ser ampliada, e as políticas públicas devem ser questionadas quanto a seu formato compensatório. Há de se considerar a equidade na formulação e efetivação das políticas de juventude, pois a "pluralidade de situações e a multiplicação de descontinuidades e estatutos híbridos e provisórios" que atravessam a experiência juvenil impossibilitam a análise da juventude como grupo homogêneo, com os mesmos códigos, interesses e práticas (Ferro, 2010, p. 75).

Os acontecimentos listados acima têm uma estreita relação com a discussão sobre juventude e projeto de vida. Notamos que, na maioria das vezes, as pautas que compõem esses eventos incluem temas como educação e trabalho, estes pensados como vias de acesso dos jovens à cidadania ou a possibilidades de um futuro melhor. No campo da educação, por exemplo (não falamos apenas da educação formal), destaca-se uma série de projetos sociais com açôes complementares que, em alguma instância, são propostos como possibilidades de inserção do jovem na sociedade ou ainda legitima uma necessidade da "ocupação" do tempo livre desse segmento populacional, que tem um claro pertencimento de classe, território e raça, são pobres, negros e pardos e moradores das periferias, revelando uma estratégia de afastamento do jovem da criminalidade (Franch, 2002).

Desse modo, é importante destacar que, diante dessa diversidade de situações, muitas das quais evidenciam profundas desigualdades entre os jovens brasileiros, está claro que são diferentes as demandas e necessidades de cada grupo desse segmento. Também a participação, ainda que tímida e restrita, dos jovens em espaços consagrados para o exercício da política (Conselho Nacional de Juventude, associação de moradores, grêmio estudantil) pode repercutir em seus projetos de vida, em meio aos "tensionamentos" inter e intrageracionais próprios ao campo da participação política.

O campo-tema juventude, como contexto de produção discursiva e práticas sociais, carrega consigo o agonismo das questôes de grande relevância social, pois, se por um lado, a visibilidade política da juventude ganhou destaque no campo dos direitos, por outro, a dinâmica do particular e do universal e da agentividade 
e subalternização complexificam a leitura sobre concepções, programas e projetos voltados "para" ou formulados "por" esse segmento populacional.

\section{DOS PERÍODOS DE PUBLICAÇÃO E UNIVERSIDADES, DAS METODOLOGIAS E REFERENCIAIS TEÓRICOS ADOTADOS: A GUISA DE UM RECONHECIMENTO DO CAMPO-TEMA}

O maior número de produções que discute "jovens e projetos de vida" se concentra a partir de 2006. Identificamos, nesses achados, consonâncias com o cenário nacional da época.

Em 2005, o Brasil registrou a maior população jovem da sua história, com 53 milhôes de jovens, diante de uma população de 181.586.030 habitantes. Além desse alastramento da população jovem, no mesmo ano, o Mapa da Violência no Brasil ${ }^{3}$ apresentou índices elevados envolvendo jovens (como vítimas e como autores) o que gerou, inclusive, uma edição especial do Mapa em 2006, intitulada Juventude e Violência.

Dados como estes influenciaram a implementação da Lei $n^{\circ} 11.129$, de 30 de junho de 2005, que instituiu o Projovem, criou o Conjuve e a Secretaria Nacional de Juventude, indicando o reconhecimento da juventude, pelo Estado brasileiro, como grupo social com interesses e necessidades particulares. $\mathrm{O}$ surgimento dessas duas instâncias representou um passo importante no sentido da construção de políticas públicas voltadas a jovens e da abertura de espaços de participação e diálogo entre o Poder Público e a sociedade civil, e parece ter tido repercussão, também, numa maior produção acadêmica sobre a juventude, conforme identificamos nesta pesquisa.

As teses, dissertações e artigos analisados são do período de 2002 a 2012; observamos, contudo, uma significativa prevalência de teses entre os anos de 2007 e 2012 (30 das 48 teses); também ocorre uma prevalência de dissertações de 2007 a 2012 (41 das 45 dissertações) e uma prevalência dos artigos com publicações a partir de 2008 . Ou seja, mais de $60 \%$ das teses e mais de $90 \%$ das dissertaçōes que tratam de jovens e projetos de vida foram defendidas nos últimos cinco anos, provavelmente como reflexo dessa efusão sociopolítica vivenciada no País em torno da juventude. Ainda há concentração de temáticas e de lugares e universidades (chamando a atenção às publicações ocorridas no Sudeste), mas, sobretudo quando se trata de artigos científicos, a região Nordeste se destaca.

No que se refere às universidades brasileiras que mais produziram teses referentes à temática analisada, notamos uma maior concentração na região

3 Documento elaborado anualmente pelo Centro Brasileiro de Estudos Latino-Americanos, desde 1998, com o intuito de mapear a violência. 
Sudeste, sobretudo, no Estado de São Paulo (Unicamp, 10 teses; USP, 7 teses; e PUC-SP, 6 teses). Assim, destaca-se que 23 das 52 teses foram defendidas em Universidades de São Paulo. ${ }^{4}$

Em relação às dissertações, destacam-se produções nas regiões Sudeste e Sul, sendo 5 trabalhos produzidos na USP, 5 na UFRGS, 4 na UFV (MG) e 4 na UFBA. A abrangência dos artigos científicos também é mais diversificada, distribuídas entre as regiōes Sudeste, Sul e Nordeste: UFC (10); UFMG (8); UFPE (8); UFRJ (8); UFBA (6); e PUC-RJ (6).

As áreas de conhecimento nas quais localizamos mais teses e dissertações foram Educação (Pedagogia e Letras), Psicologia, Ciências Sociais Aplicadas (Sociologia, Antropologia e Serviço Social). Há, ainda, estudos nas áreas de Saúde Coletiva, Economia Doméstica, Comunicação, Extensão Rural e Teologia. Dos artigos científicos analisados, 45 foram da área de Psicologia social; 41 da área de Educação; e apenas 6 da área de Sociologia.

As metodologias de trabalho utilizadas nas teses, dissertações e artigos se anunciam como sendo $100 \%$ qualitativas e utilizam multimetodologias. As estratégias adotadas foram diferenciadas e sempre apareceram complementares (nenhum dos trabalhos usou apenas um método para coleta de dados): entrevistas individuais e grupais; observação participante; questionários autoaplicáveis; pesquisa bibliográfica; pesquisa etnográfica; diário de campo.

Durante a análise das metodologias dos trabalhos, identificamos que a maioria trata de pesquisas "sobre" o jovem, considerando o jovem e suas demandas, sem contextualizar a realidade vivenciada por este. Com isso corroboramos Castro (2008), que afirma que pesquisar "com" jovens em vez de "sobre" eles é uma forma de posicioná-los como edificadores do mundo no aqui e agora de suas possibilidades de ação e entendimento da vida social. Pesquisas "com" jovens, nesses termos, ainda se constituem como a minoria, precisando, portanto, que pesquisadores galguem maiores esforços para sua realização.

Quando partimos para conhecer os principais referenciais teóricos com que os estudiosos que produziram dissertações e teses dialogaram em suas pesquisas, percebemos uma diversidade de interlocuçóes: apenas um autor se destacou como mais referido: Paulo Freire (1921-1997). Ademais, aparecem autores que podemos englobar a partir de áreas de conhecimento, como Inhelder, Piaget e Erikson (Psicologia do desenvolvimento); Bourdieu, Eisenstadt e Marx (Sociologia); Foucault, Deleuze, Guattari, Latour e Morin (Filosofia). Há ainda menção a alguns referenciais como "projetos vitais", formulado por Damon; a "Sociologia do conhecimento"; o "pós-modernismo reflexivo", a "teoria dos modelos organizadores do pensamento" e a "narrativa e a consciência histórica”,

4 Além disso, encontramos trabalhos na Universidade Federal do Rio Grande do Sul (4 teses); Universidade Federal do Ceará (4 teses) e Universidade Federal de Minas Gerais (4 teses) e outras com menos expressão (apenas uma tese). 
de Paul Ricoeur e de Jörn Rüsen. No caso dos artigos científicos, nos resumos (fonte de investigação maior desta pesquisa), não houve qualquer indicação de referencial teórico ou metodológico.

\section{CONSIDERAÇÕES FINAIS}

A realização deste estudo permitiu um olhar ampliado e crítico acerca de pesquisas e reflexôes acadêmicas relacionadas à Juventude e Projeto de Vida na última década no Brasil. Pudemos acessar e conhecer que temas de pesquisas relacionadas a jovens e projetos de vida têm sido empreendidos em artigos, dissertações e teses, onde esses estudos se concentram, que métodos de estudo e autores de base têm sido referenciados, em que campos da ciência se situam.

Se partirmos, porém, em uma direção que vá além desses estudos, numa perspectiva de problematizá-los a partir de dados sociais, históricos, culturais e políticos vivenciados em nosso País, na última década, também encontraremos reverberações entre o que cientistas refletem quando pensam em projeto de vida e o que as políticas e práticas de juventude evidenciam nesse aspecto.

Chama a atenção a concentração de estudos científicos relacionados à área de Educação na última década, ao mesmo tempo em que percebemos investimentos políticos em áreas formativo-educativas nesse mesmo período, por meio, por exemplo, da implantação de políticas de educação, como o Projovem, ou programas, como o Amigos da Escola ou a Escola em Tempo Integral. Também os estudos que se referem a projetos de vida e juventude, quando tratam de temas como a participação política juvenil, podem ser relacionados a movimentos sociais e políticos evidenciados nos últimos anos, como a realização de duas Conferências Nacionais de Juventude ou de Reuniōes Especializadas da Juventude do Mercosul, que viabilizam espaços de discussão e participação de jovens.

Outro contexto que se destacou nos estudos científicos refere-se a temas relacionados a jovens pobres, à violência juvenil e a políticas públicas voltadas a essa parcela da população; nos aspectos político-históricos constatamos, nesse mesmo período dos estudos, a criação da Secretaria Nacional da Juventude e do Conselho Nacional de Juventude como estratégias políticas voltadas a atender a demandas específicas dos jovens, especialmente dos jovens pobres.

É assim que refletimos, portanto, que há diálogos (explícitos ou implícitos) que demonstram uma interlocução e sintonia entre os estudos acadêmicos sobre a juventude e contextos sociais, históricos e, principalmente, políticos, vivenciados em nosso País na última década. Preponderam estudos sobre a população jovem, 
em detrimento de reflexões sobre o campo-tema juventude. Ainda se destaca um modelo de jovem a ser estudado, que é o jovem pobre, o jovem-problema sobre quem é preciso o Poder Público intervir por meio de processos educativos, de ressocialização ou de ação social.

Este estudo indicou, contudo, que as pesquisas, na maioria das vezes, trazem um olhar "desfocado", como se estivéssemos diante de uma juventude como grupo homogêneo, sem considerar especificidades, como classes sociais, gênero, etnia. Os estudos referenciam o jovem sem uma reflexão sobre a tensão que perpassa a relação entre os termos condição e situação juvenil. Apostamos na possibilidade de estudos sobre situações juvenis e suas particularidades nas trajetórias e projetos de vida, focando na produção de conhecimento localizado e implicado em que pesquisadores refletem criticamente sobre a relação do campo-tema com o campo social ampliado, visibilizando os efeitos de poder nas/das suas produções discursivas. 


\section{REFERÊNCIAS}

Abramo, H. W. \& Branco, P. P. M (Orgs.). (2005). Retratos da juventude brasileira: análises de uma pesquisa nacional. São Paulo: Fundação Perseu Abramo; Instituto Cidadania.

Boghossian, C. \& Minayo, M. (2009). Revisão sistemática sobre juventude e participação nos últimos 10 anos. Saúde e Sociedade, 18(3), 411-423.

Castro, L. R. de \& Correa, J. (2005). Mostrando a real: um relato da juventude pobre no Rio de Janeiro. Rio de Janeiro: NAU/FAPERJ.

Castro, L. R. de. (2008). Conhecer, transformar(-se) e aprender: pesquisando com crianças e jovens. In L. R. de Castro \& V. L. Besset (Orgs.), Pesquisaintervenção na infância e juventude. (pp. 21-42). Rio de Janeiro: NAU/FAPERJ.

Dayrell, J. (2002). O rap e o funk na socialização da juventude. Educação e Pesquisa, 28(1), 117-136.

Dayrell, J. (2005). Projeto de vida e escola: a instituição escolar desconsidera o jovem por trás do aluno. Onda Jovem, 1(1), 34-37.

Dayrell, J. (2007). O jovem como sujeito social. In: O. Fávero, M. Sposito, P. Carrano, \& R. Novaes (Orgs.), Juventude e contemporaneidade. (pp. 155-179). Brasília: UNESCO; MEC; Anped.

Fausto Neto, A. M. \& Quiroga, C. (1998, março). Juventude urbana pobre: manifestações públicas e leituras sociais. Contemporaneidade e Educação, Rio de Janeiro, 3(3), 142-152.

Ferreira, N. (2002). As pesquisas denominadas “estado da arte”. Revista Educação \& Sociedade, 79, 257-272.

Ferro, L. (2010). O graffiti mediador: reflexões sobre as metamorfoses da prática em três cidades. In: G. Velho \& L. F. D. D. Duarte (Org.), Juventude contemporânea: culturas, gostos e carreiras. Rio de Janeiro: Letras.

Franch, M. (2002). Nada para fazer? Um estudo sobre atividades no tempo livre entre jovens de periferia no Recife. Revista Brasileira de Estudos de População, 19(2), 117-134.

Lei no 11.129, de 30 de junho de 2005. (2005, 30 de junho). Instituiu o Programa Nacional de Inclusão de Jovens (Projovem), cria o Conselho 
Nacional da Juventude (Conjuve) e a Secretaria Nacional de Juventude. Diário Oficial da União, Brasília. Recuperado a partir de http://www.planalto.gov.br/ ccivil_03/_Ato2004-2006/2005/Lei/L11129.htm

Mayorga, C. (2013). Pesquisar a juventude e sua relação com a política: notas metodológicas. Estudos de Psicologia, 2(18), 343-350.

Minayo, M. \& Sanches, O. (1993). Quantitativo-qualitativo: oposição ou complementaridade? Cadernos de Saúde Pública, 9(3), 239-262.

Peralva, A. (2007). O jovem como modelo cultural. In: O. Fávero, M. Sposito, P. Carrano, \& R. Novaes (Orgs.), Juventude e contemporaneidade. (pp. 13-29). Brasília: UNESCO; MEC; Anped.

Spink, P. K. (2003). Pesquisa de campo em Psicologia social: uma perspectiva pós-contrucionista. Psicologia \& Sociedade, 1(1), 18-42.

Telles, V. (2007). Trajetórias urbanas: fios de uma descrição da cidade. In: E. Dagnino \& L. Tatagiba (Orgs.), Democracia, sociedade civil e participação. (pp. 01-25). Chapecó: Argos.

Velho, G. (1997). Individualismo e cultura: notas para uma antropologia da sociedade contemporânea. Rio de Janeiro: Jorge Zahar. 